\title{
Inoculação de sementes com bactéria diazotrófica e aplicação de nitrogênio em cobertura e foliar em milho
}

\author{
Seeds inoculation with diazotrophic bacteria and nitrogen \\ application in side-dressing and leaf in maize
}

\author{
Claudinei Kappes ${ }^{1 *}$; Orivaldo Arf²; Marcelo Valentini Arf ${ }^{3}$; João Paulo Ferreira3; \\ Edjair Augusto Dal Bem ${ }^{4}$; José Roberto Portugal'; Rafael Gonçalves Vilela ${ }^{5}$
}

\begin{abstract}
Resumo
Considerando a importância do manejo do nitrogênio e da sua fixação biológica através de bactérias diazotróficas, conduziu-se este trabalho com o objetivo de avaliar o desempenho agronômico do milho, em função da inoculação das sementes com Azospirillum brasilense e da aplicação de nitrogênio em cobertura e foliar. O experimento foi conduzido no município de Selvíria - MS, durante o ano agrícola 2010/2011, sob Latossolo Vermelho distrófico típico argiloso (20 20' S e 51 $24^{\circ}$ ' W, com altitude de 340 $\mathrm{m})$. Foram estabelecidos dezesseis tratamentos com quatro repetições, em blocos ao acaso, resultantes da combinação dos fatores $A$. brasilense (com e sem inoculante), dose de nitrogênio ( 0 e $90 \mathrm{~kg} \mathrm{ha}^{-1}, \mathrm{em} \mathrm{V}_{5}$ ) e ureia foliar $\left(0,4,8\right.$ e $12 \%$ : aplicações em $\mathrm{V}_{5}$ e $\left.\mathrm{V}_{8}\right)$. O híbrido utilizado foi o DKB $390 \mathrm{YG}^{\circledR}$, semeado no espaçamento de $0,9 \mathrm{~m}$ entre linhas. Foram mensurados componentes morfológicos e produtivos da cultura e produtividade de grãos. Houve aumento de produtividade de grãos do milho pela inoculação das sementes com A. brasilense. A aplicação de $90 \mathrm{~kg} \mathrm{ha}^{-1}$ de nitrogênio em cobertura proporcionou maior índice de clorofila foliar, diâmetro de colmo e prolificidade, entretanto, a produtividade não foi incrementada. A aplicação de ureia foliar não apresentou eficiência agronômica e, portanto, não deve ser utilizada como única forma de fornecimento e alternativa de complementação de nitrogênio à cultura. Palavras-chave: Zea mays, Azospirillum brasilense, adubação nitrogenada, adubação foliar, produtividade
\end{abstract}

\begin{abstract}
Considering the importance of nitrogen management and its biological fixation with diazotrophic bacteria, this study was carried out aiming to evaluate the agronomic performance of maize, in response to seed inoculation with Azospirillum brasilense and nitrogen application in side-dressing and leaf. The experiment was conducted in Selvíria, Mato Grosso of Sul State, Brazil, during the growing season 2010/2011, on a clayey Rhodic Haplustox ( $20^{\circ} 20^{\prime} \mathrm{S}$ and $51^{\circ} 24^{\prime} \mathrm{W}$, with altitude of $\left.340 \mathrm{~m}\right)$. Sixteen treatments were established with four replications, in randomized blocks with the combination of the factors $A$. brasilense (with and without inoculante), nitrogen rate ( 0 and $90 \mathrm{~kg} \mathrm{ha}^{-1}$, in $\mathrm{V}_{5}$ growth stage) and urea leaf application $\left(0,4,8\right.$ and $12 \%$ : application in $\mathrm{V}_{5}$ and $\mathrm{V}_{8}$ growth stage). The maize hybrid
\end{abstract}

1 Dr. em Agronomia do Dept ${ }^{\circ}$ de Fitotecnia, Tecnologia de Alimentos e Sócio-Economia, Universidade Estadual Paulista, UNESP, Ilha Solteira, SP. E-mail: kappes.agro@gmail.com

2 Prof. Dr. do Dept ${ }^{\circ}$ de Fitotecnia, Tecnologia de Alimentos e Sócio-Economia, UNESP, Ilha Solteira, SP. E-mail: arf@agr.feis. unesp.br

3 Discente(s) de Doutorado em Agronomia, UNESP, Ilha Solteira, SP. E-mail: marceloarf@hotmail.com; ferreirajpferreira@ gmail.com

4 Discente de Mestrado em Agronomia, UNESP, Ilha Solteira, SP. E-mail: edjairflorestal@hotmail.com

5 Discente(s) em Agronomia, UNESP, Ilha Solteira, SP. E-mail: jr_portugal@hotmail.com; rafael.g.v@hotmail.com

* Autor para correspondência

Recebido para publicação 29/08/11 Aprovado em 13/02/13 
used was the DKB $390 \mathrm{YG}^{\circledR}$, sowed in the row spacing of $0.9 \mathrm{~m}$. Parameters measured were productive and morphological components of culture and crop yield. Increase in maize yield by seed inoculation with $A$. brasilense was observed. The application of $90 \mathrm{~kg} \mathrm{ha}^{-1}$ of nitrogen in side-dressing provided higher chlorophyll leaf index, stalk diameter and prolificacy, however, the yield not was increased. The application of urea leaf did not agronomic efficiency and, therefore, should not be used as the unique form of supply and alternative to nitrogen addition to crop.

Key words: Zea mays, Azospirillum brasilense, nitrogen fertilization, leaf fertilization, yield

\section{Introdução}

O nitrogênio possui papel fundamental no metabolismo vegetal por participar diretamente na biossíntese de proteínas e clorofilas (ANDRADE et al., 2003). No entanto, encontra-se em quantidades insuficientes na maioria dos solos brasileiros, demandando uma fertilização em doses adequadas para garantir o desenvolvimento e produtividade do milho (BELARMINO et al., 2003). Existe grande interesse dos produtores em práticas alternativas que visem a redução na aplicação e aumento de eficiência na utilização de insumos nas áreas de produção agrícola. Dentre os processos biológicos que ocorrem na natureza, a fixação biológica do nitrogênio atmosférico é realizada por um grupo restrito de bactérias, denominadas diazotróficas. Dentre estas, as do gênero Azospirillum, principalmente a espécie $A$. brasilense, tem sido usada como inoculante em diversas culturas, tais como: cereais, algodão, cana-de-açúcar, café, braquiárias e outras (REIS, 2007).

A interação positiva entre estas bactérias e o milho tem sido demonstrada por vários autores e, embora o maior obstáculo para a utilização desta tecnologia é a inconsistência de resultados em condições de campo, ligada a fatores como condições edafoclimáticas e interações com a biota do solo (DOBBELAERE et al., 2001; REIS, 2007), levantamentos de diversos experimentos realizados em vários países mostram que a inoculação com Azospirillum resultou, na maioria dos casos, em aumento de matéria seca, produtividade e acúmulo de nitrogênio (OKON; VANDERLEYDEN, 1997). Outras revisões, também apresentam resultados positivos do uso destes produtos para a agricultura
(KENNEDY; CHOUDHURY; KECSKÉS, 2004; LUCY; REED; GLICK, 2004). Apesar de muitos anos de pesquisa, ainda se observam respostas muito variáveis, o que mostra a importância e justifica a realização de experimentos de campo.

Sabe-se que existem interações entre o nitrogênio e as bactérias diazotróficas na assimilação e utilização desse nutriente pelas plantas. Ferreira, Fernandes e Döbereiner (1987) observaram que bactérias do gênero Azospirillum podem atuar no crescimento vegetal por meio da redução do nitrato nas raízes das plantas. Desse modo, as plantas não gastariam energia para reduzir o nitrato até amônia e essa energia poderia ser canalizada para outros processos vitais. O conhecimento desta interação pode constituir estratégia importante e contribuir com informações valiosas no que se refere à redução de aplicação de fertilizantes nitrogenados, redução de custos na semeadura e menor contaminação do lençol freático por compostos nitrogenados.

Pouco se conhece sobre as situações nas quais os fertilizantes foliares podem complementar os fertilizantes aplicados via solo, visando aumento da eficiência de uso do nutriente, da produtividade e lucratividade. No trabalho de Deuner et al. (2008), os autores concluíram que a aplicação de nitrogênio foliar pode ser uma maneira eficiente para complementar o que é absorvido pelas raízes, no entanto, não deve ser utilizada como única forma de fornecimento de nitrogênio às plantas $e$ deve-se atentar para a concentração a ser utilizada. A ureia é indicada para aplicação foliar por conter alta concentração de nitrogênio e alto grau de solubilidade. O risco de causar injúrias nas folhas é menor para a ureia em relação às outras fontes 
de nitrogênio, se comparadas soluções com concentrações equivalentes (BOARETTO et al., 1999).

Estudos envolvendo aplicação de ureia foliar são extremamente importantes, pois essa prática pode trazer problemas ao desenvolvimento da planta em caso de fitotoxicidade causada pelo fertilizante. No Brasil, poucos estudos têm enfocado a interação adubação nitrogenada e bactérias diazotróficas em milho geneticamente modificado.

Tendo em vista a importância da fixação biológica e do manejo do nitrogênio, conduziu-se este trabalho com o objetivo de avaliar o desempenho agronômico do milho, cultivado em sistema plantio direto, em função da inoculação das sementes com
Azospirillum brasilense e da aplicação de nitrogênio em cobertura e foliar.

\section{Material e Métodos}

O experimento foi conduzido no município de Selvíria, Estado de Mato Grosso do Sul, em área experimental situada a $20^{\circ} 20^{\prime}$ Sul e $51^{\circ} 24^{\prime}$ Oeste, com $340 \mathrm{~m}$ de altitude. O clima da região, segundo classificação de Köppen, é do tipo Aw, com precipitação pluvial média anual de 1.330 $\mathrm{mm}$, temperatura média anual de $25^{\circ} \mathrm{C}$ e umidade relativa do ar média anual de 66\% (CENTURION, 1982). Os dados climáticos coletados na Estação Metereológica da Fazenda Experimental durante o ciclo da cultura podem ser observados na Figura 1.

Figura 1. Dados diários de precipitação pluvial, temperatura mínima e máxima do ar e umidade relativa do ar (UR) durante a condução do experimento. Selvíria - MS, Brasil (2010/2011).

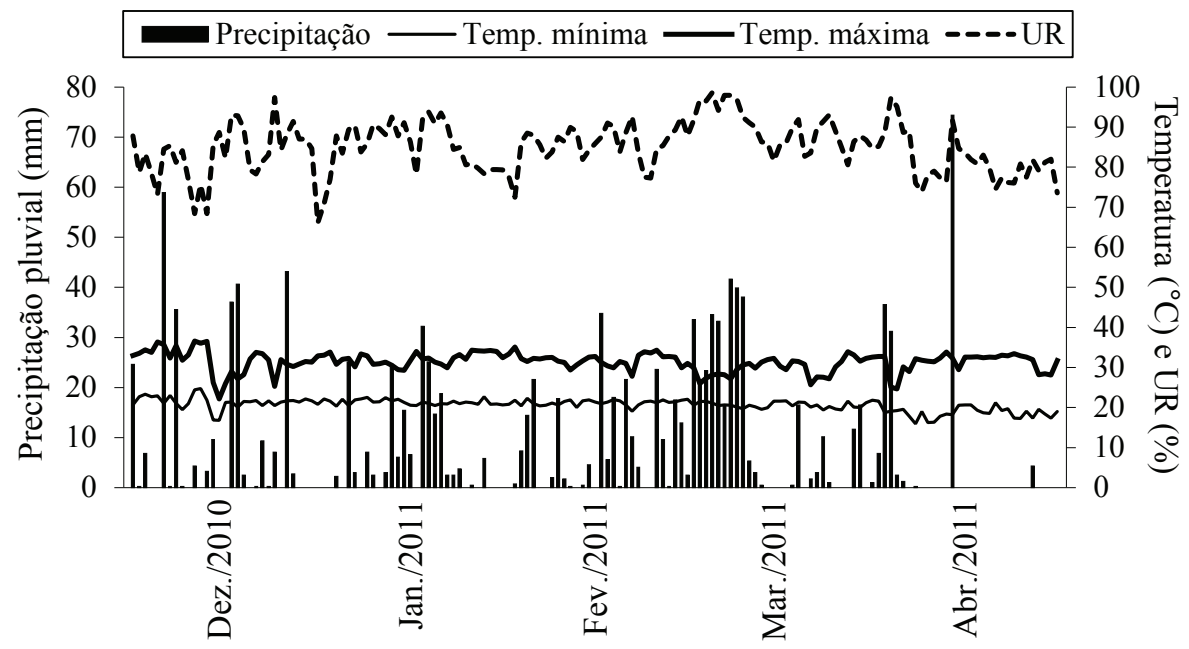

Fonte: Elaboração dos autores.

O solo da área experimental é classificado como Latossolo Vermelho distrófico álico e de textura argilosa (EMBRAPA, 2006), cuja análise química (camada de 0,0 a 0,2 m), está apresentada na Tabela 1. Não houve preparo do solo, pois se trata de área cultivada há 08 anos com sistema plantio direto. No período de inverno anterior a instalação do experimento, a área foi ocupada com Crotalaria juncea. 
Tabela 1. Análise química do solo da área experimental na camada de 0,0 a $0,2 \mathrm{~m}$ antes da instalação do experimento. Selvíria - MS, Brasil (2010/2011).

\begin{tabular}{|c|c|c|c|c|c|c|c|c|c|}
\hline \multirow{2}{*}{$\underset{\mathrm{CaCl}_{2}}{\mathbf{p H}}$} & $\mathbf{P}^{(1)}$ & $\mathbf{S}$ & $\mathbf{K}$ & $\mathrm{Ca}$ & Mg & $\mathrm{H}+\mathrm{Al}$ & CTC & $\mathbf{V}$ & MO \\
\hline & \multicolumn{2}{|c|}{$\mathrm{mg} \mathrm{dm}^{-3}$} & & & ${ }_{c} \mathrm{dn}$ & 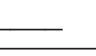 & & $-\%-$ & $\mathrm{g} \mathrm{dm}^{-3}$ \\
\hline 5,5 & 29 & 7 & 2,7 & 31 & 18 & 33 & 85 & 61 & 17 \\
\hline
\end{tabular}

(1) Método da resina.

Fonte: Elaboração dos autores.

Foram estabelecidos dezesseis tratamentos com quatro repetições, resultantes da combinação dos fatores $A$. brasilense, nitrogênio em cobertura e ureia foliar. O delineamento experimental foi o de blocos ao acaso, em esquema misto de faixas e fatorial. Os tratamentos com $A$. brasilense foram dispostos em faixas dentro de cada bloco e as combinações nitrogênio em cobertura $\mathrm{x}$ ureia foliar foram locadas em esquema fatorial $2 \times 4$ dentro de cada faixa de A. brasilense. As parcelas foram constituídas por quatro linhas de 5,0 m de comprimento, espaçadas de $0,9 \mathrm{~m}$ entre si. Para a coleta dos dados foram utilizadas as duas linhas centrais, perfazendo área útil de $9,0 \mathrm{~m}^{2}$.

As sementes foram inoculadas no momento da semeadura, utilizando-se inoculante Azototal $^{\circledR}$ com as estirpes Abv5 e Abv6 de A. brasilense (2 x $10^{8}$ células viáveis $\mathrm{mL}^{-1}$ ) na dose de $8 \mathrm{~mL} \mathrm{~kg}^{-1}$ de semente. Foi utilizado o híbrido simples DKB $390 \mathrm{YG}^{\circledR}\left(\right.$ Dekalb $\left.^{\circledR}\right)$, ciclo precoce (845 graus dia) e grãos semi-duros amarelo-alaranjado. A aplicação do nitrogênio em cobertura foi realizada quando $50 \%$ das plantas de milho apresentavam a quinta folha expandida $\left(\mathrm{V}_{5}\right)$, tendo como fonte a ureia, correspondente a dose de $90 \mathrm{~kg} \mathrm{ha}^{-1}$ de $\mathrm{N}$, a qual foi determinada naclasse de resposta média ao nitrogênio e na produtividade esperada de 8.000 a 10.000 $\mathrm{kg} \mathrm{ha}{ }^{-1}$. A aplicação foi realizada manualmente, distribuindo a ureia sobre a superfície do solo (sem incorporação), ao lado e aproximadamente $5,0 \mathrm{~cm}$ da linha de semeadura, a fim de evitar o contato do fertilizante com as plantas. É válido ressaltar, que no momento da aplicação, o solo apresentavase com boas condições de umidade. Ademais, no dia seguinte à aplicação, constatou-se precipitação pluvial de $25 \mathrm{~mm}$.

As concentrações de ureia foliar foram: 0, 4, 8 e $12 \%$. Foram realizadas duas aplicações em diferentes estádios de desenvolvimento (RITCHIE; HANWAY; BENSON, 2003), mantendo tais concentrações: a primeira, realizada simultaneamente com a aplicação de nitrogênio em cobertura $\left(\mathrm{V}_{5}\right)$ e; a segunda, quando $50 \%$ das plantas de milho apresentavam-se com a oitava folha expandida $\left(\mathrm{V}_{8}\right)$. O intervalo entre as aplicações foliares foi de 14 dias. As aplicações foram realizadas com pulverizador costal manual com capacidade de pressão de trabalho de $6 \mathrm{kgf}$ $\mathrm{cm}^{-2}$, munido de bico contendo ponta do tipo jato cone vazio e volume de calda aproximado de $170 \mathrm{~L}$ $\mathrm{ha}^{-1}$. As aplicações de ureia foliar foram realizadas no final de tarde, momento em que as condições ambientais se encontravam adequadas às aplicações (umidade relativa do ar de $85 \%$, temperatura média de $27^{\circ}$ e velocidade do vento de $8 \mathrm{~km} \mathrm{~h}^{-1}$ ). Após as aplicações de ureia foliar, avaliou-se por meio de sintoma visual em cada parcela, a fitotoxicidade provocada pelo nitrogênio; entretanto, nenhum efeito desta natureza foi verificado na cultura, mesmo perante a maior concentração de ureia foliar $(12 \%)$.

Previamente a semeadura do milho, as plantas daninhas presentes na área foram dessecadas com glifosato (1.440 $\left.\mathrm{g} \mathrm{ha}^{-1}\right)$ e 2,4-D sal dimetilamina $\left(806 \mathrm{~g} \mathrm{ha}^{-1}\right)$. A semeadura foi realizada no dia 10 de dezembro de 2010, distribuindo-se seis sementes por metro de sulco, no espaçamento de $0,9 \mathrm{~m}$ entre as linhas. A emergência da maioria das plântulas ocorreu aos seis dias após a semeadura 
e a população inicial estabelecida foi de 65.260 plantas $\mathrm{ha}^{-1}$, estando coerente com a recomendação da empresa produtora das sementes. Na adubação mineral de semeadura de toda a área experimental foram aplicados $400 \mathrm{~kg} \mathrm{ha}^{-1}$ da fórmula $08-28-16$, totalizando no fornecimento de 32, 112 e $64 \mathrm{~kg} \mathrm{ha}^{-1}$ de $\mathrm{N}, \mathrm{P}_{2} \mathrm{O}_{5}$ e $\mathrm{K}_{2} \mathrm{O}$, respectivamente. Utilizou-se semeadora específica para o sistema plantio direto, equipada com mecanismo sulcador de hastes (tipo "botinha") e sistema de distribuição de sementes pneumático.

Durante a condução da cultura foram realizadas as práticas fitotécnicas de acordo com a sua necessidade. As plantas daninhas foram controladas em pós-emergência utilizando-se os herbicidas atrazina (1.000 $\left.\mathrm{g} \mathrm{ha}^{-1}\right)$ e tembotriona (100 $\left.\mathrm{g} \mathrm{ha}^{-1}\right)$. Adicionou-se na calda de aplicação o adjuvante éster metilado de óleo de soja (720 $\left.\mathrm{g} \mathrm{ha}^{-1}\right)$. No momento da aplicação, as plantas daninhas estavam nos estádios inicias de desenvolvimento e a cultura encontrava-se com $50 \%$ das plantas com a quinta folha expandida. $O$ intervalo entre a primeira aplicação de ureia foliar e a de herbicida foi de dois dias. As aplicações dos produtos fitossanitários foram realizadas com pulverizador de barras tratorizado, com volume de calda equivalente a 200 $\mathrm{L} \mathrm{ha}^{-1}$. Não houve a necessidade de manejo químico da lagarta-do-cartucho [Spodoptera frugiperda (J.E. Smith)] por se tratar de um genótipo com tecnologia Bt.

Durante o desenvolvimento da cultura, foi realizada a estimativa do teor de clorofila foliar com a utilização do clorofilômetro portátil ClorofiLOG ${ }^{\circledR}$ (modelo CFL 1030), que por meio de sensores, analisa três faixas de frequência de luz e através de relações de absorção de diferentes frequências, fornece medições dos teores das clorofilas $a, b$ e total $(a+b)$, expressas em unidades dimensionais chamadas ICF (Índice de Clorofila Foliar). As leituras foram realizadas, em três plantas escolhidas aleatoriamente na área útil de cada parcela, em três estádios de desenvolvimento. A primeira, quando $50 \%$ das plantas apresentavam-se com cinco folhas expandidas (momento da aplicação do nitrogênio em cobertura e da primeira aplicação de ureia foliar); a segunda, quando $50 \%$ das plantas apresentavamse com oito folhas expandidas (momento da segunda aplicação de ureia foliar) e; a terceira, no florescimento pleno da cultura (RITCHIE; HANWAY; BENSON, 2003). A primeira e segunda leitura foram realizadas na porção do terço central do limbo da última folha expandida e a terceira leitura na folha oposta e abaixo da espiga principal.

O florescimento pleno $(50 \%$ das plantas no início da polinização) ocorreu aos 50 dias após a emergência. Quando a cultura encontrava-se com as espigas em estádio de grãos pastosos, foram mensuradas em cinco plantas por parcela, as seguintes características: diâmetro de colmo (diâmetro do segundo internódio, a partir da base da planta), altura de planta (medição do colo até a inserção da folha "bandeira") e de espiga (medição do colo até a inserção da primeira espiga viável com o colmo).

A colheita foi realizada no dia 15 de abril de 2011 (120 dias após a emergência), sendo avaliado em cinco espigas ao acaso por parcela: número de fileiras de grãos por espiga, diâmetro de espiga (porção mediana da espiga) e comprimento de espiga. Além disso, determinou-se a população final de plantas e a prolificidade (relação entre o número de espigas colhidas e o número de plantas na área útil da parcela) na ocasião da colheita. A produtividade foi obtida a partir da trilha mecânica e pesagem dos grãos oriundos das espigas colhidas na área útil das parcelas, a qual foi convertida para $\mathrm{kg} \mathrm{ha}^{-1}$ e corrigida para $13 \%$ de umidade (base úmida - b.u.). Em seguida, mensurou-se a massa de mil grãos (pesagem de uma subamostra de 250 grãos por parcela, em balança de precisão $(0,001 \mathrm{~g})$, extrapolando-se para mil grãos e corrigindo-se para $13 \%$ de umidade - b.u.).

Os resultados foram submetidos ao teste $\mathrm{F}$ da análise de variância (ANAVA), comparando-se as médias dos tratamentos com $A$. brasilense e com 
nitrogênio em cobertura pelo teste de Tukey a 5\% de probabilidade, de acordo com Pimentel Gomes e Garcia (2002). As médias de concentrações de ureia foliar foram submetidas à análise de regressão (BANZATTO; KRONKA, 2006), ajustando-se modelos de equações significativas pelo teste $\mathrm{F}$, para melhor discussão dos resultados. O aplicativo computacional utilizado foi o SISVAR.

\section{Resultados e Discussão}

Os dados climáticos (Figura 1) indicam que durante a condução do experimento, a temperatura do ar foi adequada para o desenvolvimento da cultura, haja vista que o milho produz melhor em temperaturas moderadas, entre 18 e $25^{\circ} \mathrm{C}$. Elevadas temperaturas noturnas não são benéficas para a produção do milho, pois proporciona redução acentuada do ciclo da planta, em função do incremento da somatória térmica, conforme citado por Fancelli e Dourado Neto (2004). Do mesmo modo, a precipitação pluvial foi adequada, havendo disponibilidade hídrica favorável para o crescimento e desenvolvimento das plantas, mineralização da matéria orgânica do solo e aproveitamento do nitrogênio pelas plantas. Estresse hídrico na cultura do milho, além de limitar o desenvolvimento da espiga e a translocação de carboidratos para os grãos, pode também afetar a resposta da planta ao nitrogênio (FANCELLI; DOURADO NETO, 2004). A velocidade de mineralização do nitrogênio está relacionada com o tipo de matéria orgânica e condições ambientais que condicionam a atividade dos microrganismos decompositores (MAR et al., 2003).

A inoculação das sementes de milho com $A$. brasilense proporcionou maior índice de clorofila foliar na primeira leitura (Tabela 2), podendo ser resultado tanto da fixação biológica do nitrogênio atmosférico, quanto dos mecanismos de promoção do crescimento, que podem incrementar a capacidade das plantas em absorver este nutriente do solo (DOBBELAERE et al., 2001). Jordão et al. (2010) também constataram efeito positivo da inoculação das sementes de milho com Azospirillum brasiliense, em que o índice de clorofila foliar foi maior nos tratamentos com a presença da bactéria diazotrófica em relação aos tratamentos onde não houve inoculação. $O$ efeito da inoculação não se manteve para a segunda e terceira leitura, porém, verificou-se que na ausência da aplicação de nitrogênio em cobertura, as plantas apresentaram menor índice de clorofila foliar em ambas as leituras. A aplicação de ureia foliar, no presente estudo, não alterou o índice de clorofila foliar na terceira leitura.

O diâmetro de colmo foi influenciado pela aplicação de nitrogênio em cobertura e pela interação entre nitrogênio em cobertura e ureia foliar (Tabela 2). Em todas as concentrações de aplicação de ureia foliar, exceto para $12 \%$, a aplicação de $90 \mathrm{~kg} \mathrm{ha}^{-1}$ de nitrogênio favoreceu a obtenção de plantas com maior diâmetro de colmo (Tabela 3 ). $\mathrm{O}$ aumento do diâmetro de colmo com a aplicação de nitrogênio mostra-se ser vantajoso, pois esta característica morfológica é uma das que mais tem sido relacionada com o percentual de acamamento e quebramento de planta na cultura do milho. Além disso, o diâmetro de colmo é muito importante para a obtenção de alta produtividade, pois quanto maior o seu diâmetro, maior a capacidade da planta em armazenar fotoassimilados que contribuirão com o enchimento dos grãos (KAPPES et al., 2011). Contudo, o efeito dos tratamentos sobre o diâmetro de colmo não se refletiu na produtividade do milho. Nota-se que com a aplicação de nitrogênio em cobertura, houve comportamento quadrático do diâmetro de colmo em resposta ao incremento na concentração de aplicação de ureia foliar (Figura 2). O modelo ajustado permitiu estimar que a aplicação de ureia na concentração de 4,7\% proporcionou o máximo diâmetro de colmo, que foi $22,2 \mathrm{~mm}$. A partir desta concentração, houve decréscimo no diâmetro de colmo das plantas, indicando que este pode ter sido um nível elevado ou tóxico de ureia, afetando negativamente este componente morfológico. 
Tabela 2. Resumo da análise de variância e valores médios de índice de clorofila foliar (ICF), diâmetro de colmo (DC), altura de planta (AP) e altura de inserção de espiga (AE) de milho em função da inoculação de sementes com $A$. brasilense e aplicação de nitrogênio em cobertura e ureia foliar. Selvíria - MS, Brasil (2010/2011).

\begin{tabular}{|c|c|c|c|c|c|c|c|}
\hline \multirow{2}{*}{\multicolumn{2}{|c|}{ Tratamentos }} & \multicolumn{3}{|c|}{$\mathrm{ICF}$} & \multirow{2}{*}{$\begin{array}{c}\mathrm{DC} \\
-\mathrm{mm}- \\
\end{array}$} & \multirow[t]{2}{*}{$\mathbf{A P}$} & \multirow{2}{*}{$\mathbf{A E}$} \\
\hline & & $1^{a}$ leitura & $2^{a}$ leitura & $3^{a}$ leitura & & & \\
\hline \multicolumn{8}{|c|}{ A. brasilense (A) } \\
\hline \multicolumn{2}{|c|}{ Com } & $40,3 \mathrm{a}$ & 48,6 & 61,2 & 20,6 & $215,7 \mathrm{a}$ & $115,0 \mathrm{a}$ \\
\hline \multicolumn{2}{|l|}{ Sem } & $38,6 \mathrm{~b}$ & 49,4 & 59,0 & 20,6 & $203,1 \mathrm{~b}$ & $111,8 \mathrm{~b}$ \\
\hline \multicolumn{8}{|c|}{$\mathrm{N}$ em cobertura $(\mathrm{N})$} \\
\hline \multicolumn{2}{|l|}{$0 \mathrm{~kg} \mathrm{ha}^{-1}$} & - & $45,8 \mathrm{~b}$ & 57,3 b & 19,6 & 210,1 & 113,7 \\
\hline \multicolumn{2}{|l|}{$90 \mathrm{~kg} \mathrm{ha}^{-1}$} & - & $52,8 \mathrm{a}$ & $62,9 \mathrm{a}$ & 21,6 & 208,8 & 113,1 \\
\hline \multicolumn{8}{|c|}{ Ureia foliar (U) } \\
\hline \multicolumn{2}{|l|}{$0 \%$} & - & - & 60,5 & 20,7 & 205,9 & 113,1 \\
\hline \multicolumn{2}{|l|}{$4 \%$} & - & - & 59,8 & 20,3 & 208,2 & 114,0 \\
\hline \multicolumn{2}{|l|}{$8 \%$} & - & - & 60,2 & 21,1 & 212,2 & 114,6 \\
\hline \multicolumn{2}{|l|}{$12 \%$} & - & - & 59,9 & 20,3 & 211,4 & 112,0 \\
\hline \multirow{7}{*}{ Valor $\mathrm{F}^{(1)}$} & $\mathrm{A}$ & $4,99 *$ & 0,93 & 3,49 & 0,01 & $20,8 * *$ & $4,54 *$ \\
\hline & $\mathrm{N}$ & - & $62,9 * *$ & $21,8 * *$ & $39,5 * *$ & 0,19 & 0,13 \\
\hline & $\mathrm{U}$ & - & - & 0,07 & 1,74 & 1,11 & 0,57 \\
\hline & $A \times N$ & - & 0,17 & 2,37 & 0,02 & 0,01 & 0,01 \\
\hline & $A \times U$ & - & - & 0,69 & 0,96 & 0,79 & 0,59 \\
\hline & $\mathrm{NxU}$ & - & - & 0,70 & $4,37 * *$ & 0,07 & 0,77 \\
\hline & $\mathrm{A} \times \mathrm{N} \times \mathrm{U}$ & - & - & 0,11 & 0,69 & 0,15 & 0,46 \\
\hline \multicolumn{2}{|l|}{ CV (\%) } & 7,79 & 6,59 & 7,91 & 5,95 & 5,27 & 5,23 \\
\hline \multicolumn{2}{|l|}{ Média geral } & 39,4 & 49,0 & 60,1 & 20,6 & 209,4 & 113,4 \\
\hline
\end{tabular}

(1) Teste $\mathrm{F}: * * \mathrm{e}^{*}$ - significativo a $1 \%$ e $5 \%$ de probabilidade, respectivamente; Médias seguidas por letra distinta nas colunas diferem pelo teste de Tukey a 5\% de probabilidade; CV - coeficiente de variação.

Fonte: Elaboração dos autores.

Figura 2. Diâmetro de colmo de plantas de milho em função da aplicação de nitrogênio em cobertura e ureia foliar. Selvíria - MS, Brasil (2010/2011). Teste F: $\left.{ }^{*}\right)$ Significativo a 5\% de probabilidade.

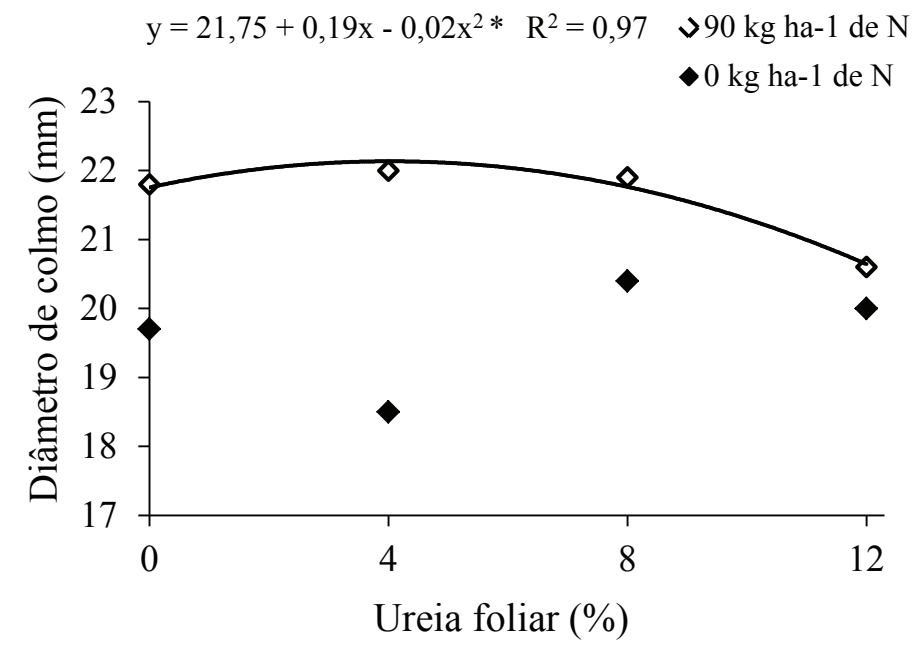

Fonte: Elaboração dos autores. 
Tabela 3. Diâmetro de colmo $(\mathrm{mm})$ de plantas de milho em função da aplicação de nitrogênio em cobertura e ureia foliar. Selvíria - MS, Brasil (2010/2011).

\begin{tabular}{lcccc}
\hline \multirow{2}{*}{ N em cobertura } & \multicolumn{5}{c}{ Ureia foliar (\%) } \\
\cline { 2 - 5 } & $\mathbf{0}$ & $\mathbf{4}$ & $\mathbf{8}$ & $\mathbf{1 2}$ \\
\hline $0 \mathrm{~kg} \mathrm{ha}^{-1}$ & $19,7 \mathrm{~b}$ & $18,5 \mathrm{~b}$ & $20,4 \mathrm{~b}$ & $20,0 \mathrm{a}$ \\
$90 \mathrm{~kg} \mathrm{ha}^{-1}$ & $21,8 \mathrm{a}$ & $22,0 \mathrm{a}$ & $21,9 \mathrm{a}$ & $20,6 \mathrm{a}$ \\
\hline
\end{tabular}

Médias seguidas por letra distinta nas colunas diferem pelo teste de Tukey a $5 \%$ de probabilidade.

Fonte: Elaboração dos autores.

A inoculação das sementes com $A$. brasilence proporcionou maior altura de planta e de inserção de espiga (Tabela 2), discordando dos resultados obtidos por Cavallet et al. (2000), em que a inoculação das sementes de milho com Azospirillum spp. não influenciou a altura de planta. Quando os estudos com as associações entre plantas e Azospirillum tiveram seu início, acreditava-se que os benefícios obtidos eram essencialmente derivados da fixação biológica do nitrogênio atmosférico (DOBBELAERE et al., 2001); no entanto, estudos posteriores demonstraram que os efeitos positivos proporcionados por estes microrganismos eram, principalmente, derivados de alterações morfológicas e fisiológicas nas raízes das plantas inoculadas, acarretando um incremento na absorção de água e nutrientes (OKON; VANDERLEYDEN, 1997). Provavelmente, neste experimento, a maior altura de planta e de inserção de espiga verificada em plantas inoculadas seja devida à produção de substâncias promotoras de crescimento pelas bactérias. Bashan e Holguin (1997) relataram ser óbvio que fitormônios, principalmente o ácido indol-acético (AIA), excretados por Azospirillum desempenham papel essencial na promoção do crescimento de plantas em geral. Em contrapartida, no presente estudo, tais características morfológicas não foram influenciadas pela aplicação de nitrogênio em cobertura e ureia foliar.

As populações inicial e final de plantas não foram influenciadas pela inoculação das sementes com A. brasilense e aplicações de nitrogênio em cobertura e ureia foliar (Tabela 4), fato esse importante para a adoção de tais tecnologias. Além disso, tal constatação permite afirmar que as demais características agronômicas avaliadas no presente estudo não foram influenciadas pela população de plantas. De modo similar, constatou-se que o número de fileiras de grãos por espiga e diâmetro de espiga não foram influenciados pela inoculação das sementes com $A$. brasilense e aplicações de nitrogênio em cobertura e ureia foliar (Tabela 4), corroborando com os resultados observados por Cavallet et al. (2000). Ohland et al. (2005) avaliando o efeito de culturas de cobertura do solo e o manejo da adubação nitrogenada em cobertura do milho cultivado em sistema plantio direto, também não verificaram diferença para o diâmetro de espiga. Por outro lado, Kappes et al. (2009) avaliaram a influência de épocas de aplicação e fontes de nitrogênio (ureia, sulfato de amônio e sulfonitrato de amônio) em cobertura no milho "safrinha" em sistema plantio direto, e ao término da pesquisa, os referidos autores concluíram que a aplicação de nitrogênio quando as plantas apresentavam dez folhas expandidas, proporcionou maior diâmetro de espiga, comprimento de grão, número de fileiras de grãos por espiga e produtividade, independente da fonte nitrogenada.

O comprimento de espiga foi maior com a inoculação das sementes com A. brasilense (Tabela 4), representando incremento de 3,7\% em comparação ao tratamento ausente de inoculação. Cavallet et al. (2000) constataram acréscimo de $6 \%$ no comprimento de espiga nos tratamentos que receberam a inoculação das sementes com Azospirillum spp. Nota-se que a aplicação de nitrogênio em cobertura e ureia foliar não influenciou 
o comprimento médio de espiga, conforme também evidenciado por Ohland et al. (2005) após terem aplicado nitrogênio em cobertura do milho cultivado em sistema plantio direto.

A prolificidade, que expressa o número de espigas por planta, foi maior quando as sementes de milho foram inoculadas com $A$. brasilense e após a cultura ter recebido aplicação de nitrogênio em cobertura (Tabela 4). Tal resposta mostra que a competição entre as plantas pelos recursos do meio, especialmente por nutrientes, foi pequena, disponibilizando às plantas os recursos necessários para o enchimento dos grãos em mais de uma espiga por planta. Em contrapartida, Souza e Soratto
(2006) e Kappes et al. (2009) não constataram efeito da aplicação de nitrogênio em cobertura no milho sobre a prolificidade da cultura. Embora tenha se constatado efeito positivo da inoculação das sementes e da aplicação de nitrogênio em cobertura, deve-se tomar alguns cuidados na interpretação de tais resultados, pois conforme Veloso et al. (2006), quando a prolificidade aumenta, o tamanho, principalmente da segunda espiga, muitas vezes torna-se muito pequeno, além de a espiga ficar desgranada e deformada, deixando entender que o acréscimo em espigas por planta não significa aumento de produtividade de milho, apesar da sua contribuição no rendimento final.

Tabela 4. Resumo da análise de variância e valores médios de população inicial (PI) e final de plantas (PF), número de fileiras de grãos por espiga (FG), diâmetro (DE) e comprimento de espiga (CE), prolificidade (PR), massa de mil grãos (MMG) e produtividade (PROD) de milho em função da inoculação de sementes com A. brasilense e aplicação de nitrogênio em cobertura e ureia foliar. Selvíria - MS, Brasil (2010/2011).

\begin{tabular}{|c|c|c|c|c|c|c|c|c|c|}
\hline \multicolumn{2}{|c|}{ Tratamentos } & $\begin{array}{c}\text { PI } \\
\text { - plant }\end{array}$ & $\underset{P F}{P F}$ & $\begin{array}{c}\mathbf{F G} \\
-n^{\circ}\end{array}$ & DE & CE & PR & MMG $^{2}$ & PROD $^{2}$ \\
\hline \multicolumn{10}{|c|}{ A. brasilense (A) } \\
\hline \multicolumn{2}{|l|}{ Com } & 65.208 & 64.375 & 16,0 & 51,0 & $182,5 \mathrm{a}$ & $1,04 \mathrm{a}$ & 309,8 & $9.501 \mathrm{a}$ \\
\hline \multicolumn{2}{|l|}{ Sem } & 65.312 & 64.687 & 16,1 & 50,6 & $175,8 \mathrm{~b}$ & $1,01 \mathrm{~b}$ & 303,8 & $8.605 \mathrm{~b}$ \\
\hline \multicolumn{10}{|c|}{$\mathrm{N}$ em cobertura $(\mathrm{N})$} \\
\hline \multicolumn{2}{|c|}{$0 \mathrm{~kg} \mathrm{ha}^{-1}$} & - & 65.069 & 15,9 & 50,7 & 177,9 & $1,01 \mathrm{~b}$ & 307,5 & 9.137 \\
\hline \multirow{2}{*}{\multicolumn{2}{|c|}{$\begin{array}{l}90 \mathrm{~kg} \mathrm{ha}^{-1} \\
\text { Ureia foliar (U) }\end{array}$}} & - & 63.993 & 16,2 & 50,8 & 180,4 & $1,04 \mathrm{a}$ & 306,1 & 8.969 \\
\hline & & & & & & & & & \\
\hline \multicolumn{2}{|l|}{$0 \%$} & - & 66.319 & 15,8 & 50,3 & 178,2 & 1,02 & 307,9 & 9.185 \\
\hline \multicolumn{2}{|l|}{$4 \%$} & - & 63.819 & 16,2 & 51,1 & 178,2 & 1,03 & 302,5 & 8.809 \\
\hline \multicolumn{2}{|l|}{$8 \%$} & - & 63.472 & 16,1 & 51,1 & 181,2 & 1,03 & 308,1 & 9.101 \\
\hline \multicolumn{2}{|l|}{$12 \%$} & - & 64.514 & 16,1 & 50,6 & 178,9 & 1,03 & 308,6 & 9.116 \\
\hline \multirow{7}{*}{ Valor $\mathrm{F}^{(1)}$} & A & 0,01 & 0,10 & 0,19 & 0,80 & $5,32 *$ & $6,80^{*}$ & 3,16 & $8,00 * *$ \\
\hline & $\mathrm{N}$ & - & 1,21 & 3,94 & 0,08 & 0,71 & $11,04 * *$ & 0,18 & 0,64 \\
\hline & $\mathrm{U}$ & - & 1,68 & 1,30 & 1,09 & 0,24 & 0,43 & 0,72 & 0,62 \\
\hline & A x N & - & 0,03 & 1,26 & 0,49 & 0,02 & 1,90 & 0,04 & 3,64 \\
\hline & $\mathrm{A} \times \mathrm{U}$ & - & 0,13 & 0,27 & 0,90 & 0,70 & 0,24 & 0,43 & 2,84 \\
\hline & $\mathrm{Nx} \mathrm{U}$ & - & 0,07 & 0,44 & 1,88 & 0,09 & 0,57 & 1,39 & 0,60 \\
\hline & $\mathrm{A} \times \mathrm{N} \times \mathrm{U}$ & - & 1,00 & 1,65 & 0,50 & 0,09 & 0,11 & 0,43 & 0,50 \\
\hline \multirow{2}{*}{\multicolumn{2}{|c|}{$\begin{array}{l}\text { CV (\%) } \\
\text { Média geral }\end{array}$}} & 5,27 & 6,06 & 3,61 & 3,03 & 6,48 & 2,38 & 4,42 & 9,33 \\
\hline & & 65.260 & 64.531 & 16,1 & 50,8 & 179,1 & 1,03 & 306,8 & 9.053 \\
\hline
\end{tabular}

(1) Teste $\mathrm{F}: * *$ e $*$ - significativo a $1 \%$ e $5 \%$ de probabilidade, respectivamente; Médias seguidas por letra distinta nas colunas diferem pelo teste de Tukey a 5\% de probabilidade; CV - coeficiente de variação; ${ }^{(2)}$ Com base em $13 \%$ de umidade nos grãos. Fonte: Elaboração dos autores. 
A massa de mil grãos, importante componente da produtividade no milho, não foi influenciada pela inoculação das sementes com $A$. brasilense e aplicações de nitrogênio em cobertura e ureia foliar (Tabela 4), corroborando com os resultados obtidos por Souza e Soratto (2006), Cruz et al. (2008) e Kappes et al. (2009), que estudando o manejo do nitrogênio em cobertura na cultura do milho cultivado em sistema plantio direto não observaram efeito significativo na massa de grãos. De acordo com Borrás e Otegui (2001), esse é o componente da produção menos afetado por variações nas práticas de manejo e adubação. Por outro lado, tal constatação não corrobora os resultados observados por Silva et al. (2006) e Lana et al. (2009), os quais verificaram aumento na massa de grãos do milho com o incremento de doses de aplicação de nitrogênio em cobertura. Segundo Ohland et al. (2005), a massa de grãos é uma característica influenciada pelo genótipo, pela disponibilidade de nutrientes e pelas condições climáticas durante os estádios de enchimento dos grãos. De acordo com Ulger, Becker e Khant (1995), o referido componente produtivo tem alta dependência da absorção de nitrogênio pelo milho, a qual alcança um pico durante o período compreendido entre o início do florescimento e o início da formação de grãos. A deficiência de nitrogênio, neste período, pode concorrer para a formação de grãos com menor massa específica, devido a não translocação do nutriente em quantidades adequadas para os mesmos. Perante tais conceitos, pode-se inferir que a cultura não apresentou deficiência de nitrogênio e que no tratamento testemunha, o suprimento de nitrogênio pode ter ocorrido pelo fertilizante aplicado na semeadura, pela fixação biológica do nitrogênio atmosférico e/ou pela rápida decomposição dos resíduos culturais proporcionados pela Crotalaria juncea, por se tratar de uma cultura de baixa relação $\mathrm{C} / \mathrm{N}$.

A produtividade foi maior quando as sementes de milho foram inoculadas com $A$. brasilense (Tabela 4), representando, em comparação a ausência de inoculação, acréscimo de 9,4\% na produtividade da cultura. Resultados de aumento de produtividade com o uso de Azospirillum também são relatados por Sala et al. (2007), na cultura do trigo. Cavallet et al. (2000) obtiveram, na presença de aplicação de nitrogênio em cobertura, aumento de 30\% na produtividade do milho quando as sementes foram inoculadas com Azospirillum spp. Nas condições edafoclimáticas de realização do presente estudo, a aplicação de nitrogênio em cobertura e ureia foliar não foi eficiente em incrementar a produtividade do milho. A falta de resposta do milho ao nitrogênio aplicado em cobertura pode ser atribuída à cultura antecessora, perante benefícios já mencionados anteriormente. Entretanto, a presença de resposta positiva da inoculação das sementes de milho com A. brasilense sobre algumas características agronômicas consideradas, especialmente produtividade, vem a ressaltar o papel significativo das bactérias diazotróficas no desempenho desta cultura, ao mesmo tempo em que demonstra o potencial de utilização da tecnologia estudada.

No presente estudo, ressalta-se que mesmo no tratamento sem aplicação de nitrogênio em cobertura e ureia foliar, obteve-se produtividade satisfatória, a qual pode ser atribuída ao nitrogênio do fertilizante utilizado na semeadura e/ou ao nitrogênio deixado pela Crotalaria juncea, seja através da fixação biológica, seja pela rápida decomposição de seus resíduos.

\section{Conclusões}

A inoculação das sementes com Azospirillum brasilense favoreceu os componentes de produção e a produtividade de grãos do milho.

A aplicação de $90 \mathrm{~kg} \mathrm{ha}^{-1}$ de nitrogênio em cobertura proporcionou maior índice de clorofila foliar, diâmetro de colmo e prolificidade, entretanto, a produtividade não foi incrementada.

Embora não tenha ocasionado danos fitotóxicos às plantas, a aplicação de ureia foliar não apresentou 
eficiência agronômica e, portanto, não deve ser utilizada como única forma de fornecimento e alternativa de complementação de nitrogênio inorgânico à cultura.

\section{Agradecimentos}

À UNESP/Campus de Ilha Solteira, pelos recursos humanos e materiais, e à Fundação de Amparo à Pesquisa do Estado de São Paulo (FAPESP), pela bolsa de estudo concedida ao primeiro autor.

\section{Referências}

ANDRADE, A. C.; FONSECA, D. M.; QUEIROZ, D. S.; SALGADO, L. T.; CECON, P. R. Adubação nitrogenada e potássica em capim-elefante (Pennisetum purpureum Schum. cv. Napier). Ciência e Agrotecnologia, Lavras, p. 1643-1651, 2003. Edição especial.

BANZATTO, D. A.; KRONKA, S. N. Experimentação agrícola. 4. ed. Jaboticabal: FUNEP, 2006. 237 p.

BASHAN, Y.; HOLGUIN, G. Azospirillum-plant relationships: environmental and physiological advances (1990-1996). Canadian Journal of Microbiology, Ottawa, v. 43, n. 2, p. 103-121, 1997.

BELARMINO, M. C. J.; PINTO, J. C.; ROCHA, G. P.; FURTINI NETO, A. E.; MORAIS, A. R. Altura de perfilho e rendimento de matéria seca de capim-tanzânia em função de diferentes doses de superfosfato simples e sulfato de amônio. Ciência e Agrotecnologia, Lavras, v. 27, n. 4, p. 879-885, 2003.

BOARETTO, A. E.; SCHIAVINATO NETO, P.; MURAOKA, T.; OLIVEIRA, M. W.; TRIVELIN, P. C. O. Fertilização foliar de nitrogênio para laranjeira em estágio de formação. Scientia Agricola, Piracicaba, v. 56, n. 3, p. 621-626, 1999.

BORRÁS, L.; OTEGUI, M. E. Maize kernel weight response to post-flowering source-sink ratio. Crop Science, Madison, v. 41, n. 6, p. 1816-1822, 2001.

CAVAllet, L. E.; PESSOA, A. C. S.; HELMICH, J. J.; HELMICH, P. R.; OST, C. F. Produtividade do milho em resposta à aplicação de nitrogênio e inoculação das sementes com Azospirillum spp. Revista Brasileira de Engenharia Agrícola e Ambiental, Campina Grande, v. 4, n. 1, p. 129-132, 2000.

CENTURION, J. F. Balanço hídrico da região de Ilha
Solteira. Cientifica, Jaboticabal, v. 10, n. 1, p. 57-61, 1982.

CRUZ, S. C. S.; PEREIRA, F. R. S.; SANTOS, J. R.; ALBUQUERQUE, A. W.; PEREIRA, R. G. Adubação nitrogenada para o milho cultivado em sistema plantio direto, no Estado de Alagoas. Revista Brasileira de Engenharia Agrícola e Ambiental, Campina Grande, v. 12, n. 1, p. 62-68, 2008.

DEUNER, S.; NASCIMENTO, R.; FERREIRA, L. S.; BADINELLI, P. G.; KERBER, R. S. Adubação foliar e via solo de nitrogênio em plantas de milho em fase inicial de desenvolvimento. Ciência e Agrotecnologia, Lavras, v. 32, n. 5, p. 1359-1365, 2008.

DOBBELAERE, S.; CROONENBORGHS, A.; THYS, A.; PTACEK, D.; VANDERLEYDEN, J.; DUTTO, P.; LABANDERA-GONZALEZ, C.; CABALLEROMELLADO, J.; AGUIRRE, J.F.; KAPULNIK, Y.; BRENER, S.; BURDMAN, S.; KADOURI, D.; SARIG, S.; OKON, Y. Responses of agronomically important crops to inoculation with Azospirillum. Australian Journal of Plant Physiology, Melbourne, v. 28, n. 9, p. 871-879, 2001.

EMPRESA BRASILEIRA DE PESQUISA AGROPECUÁRIA - EMBRAPA. Sistema brasileiro de classificação de solos. 2. ed. Brasília: Embrapa-SPI; Rio de Janeiro: Embrapa Solos, 2006. 306 p.

FANCELLI, A. L.; DOURADO NETO, D. Produção de milho. 2. ed. Guaíba: Agropecuária, 2004. 360 p.

FERREIRA, M. C. B.; FERNANDES, M. S.; DÖBEREINER, J. Role of Azospirillum brasilense nitrate reductase in nitrate assimilation by wheat plants. Biology and Fertility of Soils, Berlin, v. 4, n. 1, p. 47-53, 1987.

JORDÃO, L. T.; LIMA, F. F.; LIMA, R. S.; MORETTI, P. A. E.; PEREIRA, H. V.; MUNIZ, A. S.; OLIVEIRA, M. C. N. Teor relativo de clorofila em folhas de milho inoculado com Azospirillum braziliense sob diferentes doses de nitrogênio e manejo com braquiária. In: FERTBIO, 2010, Guarapari. Anais... Viçosa: SBCS, 2010. 1 CD-ROM.

KAPPES, C.; ANDRADE, J.A. C.; ARF, O.; OLIVEIRA, A. C.; ARF, M. V.; FERREIRA, J. P. Desempenho de híbridos de milho em diferentes arranjos espaciais de plantas. Bragantia, Campinas, v. 70, n. 2, p. 334-343, 2011.

KAPPES, C.; CARVALHO, M. A. C.; YAMASHITA, O. M.; SILVA, J. A. N. Influência do nitrogênio no desempenho produtivo do milho cultivado na segunda safra em sucessão à soja. Pesquisa Agropecuária Tropical, Goiânia, v. 39, n. 3, p. 251-259, 2009. 
KENNEDY, I. R.; CHOUDHURY, A. T. M. A.; KECSKÉS, M. L. Non-symbiotic bacterial diazotrophs in crop-farming systems: can their potential for plant growth promotion be better exploited? Soil Biology and Biochemistry, Oxford, v. 36, n. 8, p. 1229-1244, 2004.

LANA, M. C.; WOYTICHOSKI JÚNIOR, P. P.; BRACCINI, A. L.; SCAPIM, C. A.; ÁVILA, M. R.; ALBRECHT, L. P. Arranjo espacial e adubação nitrogenada em cobertura na cultura do milho. Acta Scientiarum. Agronomy, Maringá, v. 31, n. 3, p. 433-438, 2009.

LUCY, M.; REED, E.; GLICK, B. R. Applications of free living plant growth-promoting rhizobacteria. Antonie Van Leeuwenhoek, Dordrecht, v. 86, n. 1, p. 1-25, 2004.

MAR, G. D.; MARCHETTI, M. E.; SOUZA, L. C. F.; GONÇALVES, M. C.; NOVELINO, J. O. Produção do milho safrinha em função de doses e épocas de aplicação de nitrogênio. Bragantia, Campinas, v. 62, n. 2, p. $267-$ 274, 2003.

OHLAND, R. A. A.; SOUZA, L. C. F.; HERNANI, L. C.; MARCHETTI, M. E.; GONÇALVES, M. C. Culturas de cobertura do solo e adubação nitrogenada no milho em plantio direto. Ciência e Agrotecnologia, Lavras, v. 29, n. 3, p. 538-544, 2005.

OKON, Y.; VANDERLEYDEN, J. Root-associated Azospirillum species can stimulate plants. ASM News, Washington, v. 63, n. 7, p. 364-370, 1997.

PIMENTEL GOMES, F.; GARCIA, C. H. Estatística aplicada a experimentos agronômicos e florestais: exposição com exemplos e orientações para uso de aplicativos. Piracicaba: FEALQ, 2002. 309 p.
REIS, V. M. Uso de bactérias fixadoras de nitrogênio como inoculante para aplicação em gramíneas. Seropédica: Embrapa Agrobiologia, 2007. 22 p. (Documentos, 232).

RITCHIE, S. W.; HANWAY, J. J.; BENSON, G. O. Como a planta de milho se desenvolve. Piracicaba: Potafós, 2003. 20 p. (Informações Agronômicas, 103).

SALA, V. M. R.; CARDOSO, E. J. B. N.; FREITAS, J. G.; SILVEIRA, A. P. D. Resposta de genótipos de trigo à inoculação de bactérias diazotróficas em condições de campo. Pesquisa Agropecuária Brasileira, Brasília, v. 42, n. 6, p. 833-842, 2007.

SILVA, E. C.; MURAOKA, T.; BUZETTI, S.; TRIVELIN, P. C. O. Manejo de nitrogênio no milho sob plantio direto com diferentes plantas de cobertura, em Latossolo Vermelho. Pesquisa Agropecuária Brasileira, Brasília, v. 41, n. 3, p. 477-486, 2006.

SOUZA, E. F. C.; SORATTO, R. P. Efeito de fontes e doses de nitrogênio em cobertura, no milho safrinha, em plantio direto. Revista Brasileira de Milho e Sorgo, Sete Lagoas, v. 5, n. 3, p. 395-405, 2006.

ULGER, A. C.; BECKER, A. C.; KHANT, G. Response of maize inbred lines and hybrids to increasing rates of nitrogen fertilizer. Journal of Agronomy and Crop Science, Madison, v. 159, n. 3, p. 157-163, 1995.

VELOSO, M. E. C.; DUARTE, S. N.; DOURADO NETO, D.; MIRANDA, J. H.; SILVA, E. C.; SOUSA, V. F. Doses de nitrogênio na cultura do milho, em solos de várzea, sob sistema de drenagem subterrânea. Revista Brasileira de Milho e Sorgo, Sete Lagoas, v. 5, n. 3, p. 382-394, 2006. 